\title{
Remission of childhood asthma after long-term treatment with an inhaled corticosteroid (budesonide): Can it be achieved?
}

\author{
E.E. van Essen-Zandvliet*, M.D. Hughes'++, H.J. Waalkens**, E.J. Duiverman+, \\ K.F. Kerrebijn*, and the Dutch CNSLD study group
}

\begin{abstract}
Remission of childhood asthma after long-term treatment with an inhaled corticosteroid (budesonide): Can it be achieved? E.E. van Essen-Zandvliet, M.D. Hughes, H.J. Waalkens, E.J. Duiverman, KF. Kerrebijn, and the Dutch CNSLD study group. CERS Journals Ltd 1994

ABSTRACT: This study was undertaken in order to determine whether long-term treatment with inhaled corticosteroid can induce a remission in childhood asthma, and to decide when stabilization of airway responsiveness occurred. We therefore carried out, an extended follow-up of 28-36 months in one of two groups of children who participated in a long-term intervention study.

This former study had shown that long-term (median follow-up 22 months) treatment with inhaled corticosteroid plus beta ${ }_{2}$-agonist improves symptoms, airway calibre and airway responsiveness in children with asthma, compared with betaagonist alone. On treatment with inhaled corticosteroid plus beta ${ }_{2}$-agonist, airway calibre did not further improve after $\mathbf{4}$ months, whereas the provocative dose of histamine which causes a $20 \%$ fall in forced expiratory volume in one second $\left(\mathbf{P D}_{20}\right)$ histamine showed gradual improvement without reaching an apparent plateau. Remission was defined as being symptom free during any 8 month period.

Of the 58 children originally randomized to receive $0.2 \mathrm{mg}$ salbutamol, plus $0.2 \mathrm{mg}$ budesonide, t.i.d., five children withdrew: three due to lack of motivation, one for psychological reasons, and one due to a deterioration of asthma. One patient was hospitalized because of an asthma exacerbation. Airway calibre showed no improvement after 4 months up to 36 months. Mean $\mathbf{P D}_{20}$ histamine stabilized after 20 months at 2.1 doubling doses above baseline, but at a subnormal level of $80 \mu \mathrm{g}$. Symptoms improved during the first 18 months, and may have been improving further, but slowly, during the period between 18 and 36 months. Thirty five patients $(60 \%)$ achieved a period of remission at some time during the 28-36 months of treatment. However, $23(66 \%)$ of these had a relapse.

We conclude that long-term treatment with inhaled corticosteroid improves clinical signs, airway calibre and airway responsiveness, although in most patients only up to a subnormal level. Only a minority of the patients achieve a long-lasting remission.

Eur Respir J., 1994, 7, 63-68
\end{abstract}

Depts of Paediatrics, Paediatric Respiratory Medicine, *Erasmus University of Rotterdam, University Hospital/Sophia Children's Hospital, **University Hospital/Beatrix Children Clinic, Groningen and +Juliana Children's Hospital, The Hague, The Netherlands, ${ }^{++}$Harvard School of Public Health, Boston, USA.

Correspondence: E.E.M. van Essen-Zandvliet Asthma Centre Heideheuvel

Soestdijkerstraatweg 129

1213 VX Hilversum

The Netherlands

Keywords: Asthma

budesonide

child

remission

responsiveness

Received: February 31993

Accepted after revision August 81993

This study was supported by a grant from the Netherlands' Health Research Promotion Programme (SGO).
Asthma is a chronic inflammatory disease [1-4], which is characterized by symptoms of airway obstruction such as cough, wheezing and breathlessness. Currently, the most effective drug is inhaled corticosteroid, probably because of anti-inflammatory properties $[5,6]$. Inhaled corticosteroids diminish symptoms, the need for additional beta ${ }_{2}$-agonists [7-9] and peak flow rate (PEFR) variability [9]; they improve airway calibre [7-9], and after long-term use they decrease airway responsiveness to histamine and methacholine [7, 10]. One study suggests that long-term anti-inflammatory treatment may even induce remission [7]. According to international consensus reports, the primary aim of asthma treatment could be maximal control of symptoms [11-13]. It remains to be determined whether normalization of airway responsiveness should also be an aim of treatment, as this is one of the known risk factors for symptomatic asthma in adulthood [14].

In an earlier paper we reported on the results of a double-blind, randomized, multicentre intervention study in children with moderate asthma, in which the effects of treatment, either with a beta ${ }_{2}$-agonist plus an inhaled corticosteroid or with a beta-agonist alone, were compared on airway calibre, bronchodilator response, airway responsiveness to histamine and symptoms [9]. After a median follow-up period of 22 months, this study was stopped because of the high rate of withdrawals, mainly due to an increase of symptoms in the group of patients receiving beta-agonist only. At that time, a significant improvement in lung function and airway 
responsiveness and a reduction in symptoms were observed in patients receiving inhaled corticosteroid. However, it was not clear if the full benefits of inhaled corticosteroid had been obtained by this time. Therefore, patients on beta $_{2}$-agonist plus inhaled corticosteroid continued their treatment, being followed-up for 28-36 months in order to answer the important question as to whether remission might be reached. We report here on the results of this extended follow-up.

\section{Patients and methods}

\section{Patients}

Fifty eight children, aged 7-16 yrs, with moderate asthma were selected from the out-patient clinics of two university children's hospitals and one general children's hospital. All children belonged to the group that

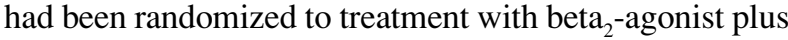
inhaled corticosteroid in the 22 month comparative study [9]. Inclusion criteria were symptomatic asthma, forced expiratory volume in one second $\left(\mathrm{FEV}_{1}\right) 55-90 \%$ of predicted and/or ratio $\mathrm{FEV}_{1} /$ forced vital capacity (FVC) $50-75 \%$; and provocative dose of histamine which causes a $20 \%$ fall in $\mathrm{FEV}_{1}\left(\mathrm{PD}_{20}\right.$ histamine) $\leq 150 \mu \mathrm{g}$ (more than two standard deviations below the mean value in healthy children [15]). Exclusion criteria were inability to follow therapy instructions and to perform reproducible lung function tests, use of oral corticosteroid, participation in a hyposensitization programme, or the presence of any concomitant disease. The study was approved by the Medical Ethics Committees of the three centres. All children and their parents gave their informed consent.

\section{Methods}

Details of methods and protocols are described in our previous publication [9], and so we give only a brief summary here. Clinical end-points for this study were symptom scores and additional beta ${ }_{2}$-agonist usage, exacerbations for which prednisolone was prescribed, absence from school because of asthma symptoms, and hospitalization. During the two week period prior to each visit, patients kept diaries of additional beta ${ }_{2}$ agonist use, and recorded whether symptoms of asthma were experienced. In addition, they measured their peak expiratory flow rate (PEFR) using a mini-Wright peak flow meter at home on three occasions each day: in the morning within half an hour of rising and prior to bronchodilation, $10 \mathrm{~min}$ after bronchodilation with $0.2 \mathrm{mg}$ salbutamol, and prior to bronchodilation in the late afternoon. Each measurement consisted of three attempts, and the highest value was recorded. The number of days on which symptoms were recorded during the 14 day period prior to a clinic visit was used as a measure of symptom burden. Functional end-points were airway calibre, measured as $\mathrm{FEV}_{1}$, and airway responsiveness, expressed as $\mathrm{PD}_{20}$ to histamine. PEFR prior to medication, both in early morning and late afternoon, was also used as a measure of airway calibre, and both its day-to-day variability and its within-day variability as additional measures of airway responsiveness. Bronchodilator response was measured both as $\mathrm{FEV}_{1}, 20 \mathrm{~min}$ after $0.8 \mathrm{mg}$ salbutamol, and as PEFR $10 \mathrm{~min}$ after 0.2 $\mathrm{mg}$ salbutamol. The co-ordinating centre in Rotterdam collected and checked all data to ensure completeness, and to prevent bias due to local procedures.

Our study had to be terminated on October 1 1991, because the financial support stopped at that time. Thus, not all patients could be followed for the period of $3 \mathrm{yrs}$ originally planned. The range of follow-up was 28-36 months.

\section{Baseline characteristics and lengths of follow-up}

Between October 1987 and April 1989, 58 patients were randomized to receive beta 2 -agonist plus inhaled corticosteroid in the comparative study [9]. Table 1 shows their baseline characteristics. All patients who had not withdrawn from this treatment continued their medication until October 1991, or until 36 months after randomization if this was earlier. Five patients withdrew from treatment. Three withdrawals occurred during the blinded comparative phase (after 4, 6 and 14 months, respectively), one because of many asthma symptoms, one for social reasons (lack of motivation), and one for psychological reasons. Two patients withdrew during the open phase (at 22 and 24 months, respectively), both due to lack of motivation. All the remaining 53 patients completed a minimum of 28 months of treatment with beta ${ }_{2}$-agonist plus corticosteroid; 50 completed 30 months and 34 finished 36 months.

\section{Definition of remission}

Since there is some ambiguity about the definition of asthma remission; we defined remission in terms of symptomatic outcome during any 8 month period preceding a clinic visit. A patient was said to be in a remission if he reported no symptoms and used no additional beta ${ }_{2}^{-}$ agonist during each of the 2 week periods prior to the four clinic visits during the 8 month period, and also took no prednisolone course, and had no hospitalization or absence from school due to asthma during the same period. The choice of an 8 month period is arbitrary, but was motivated by the fact that the group behaviour of the study cohort appeared to be stable after 20 months and up until the minimum length of follow-up of 28 months, a period spanning 8 months.

\section{Statistical methods}

To assess whether $\mathrm{FEV}_{1}, \mathrm{PD}_{20}$ and PEFR were changing after at least 18 months on treatment, a linear regression line was fitted to each subject's sequence of 
Table 1. - Characteristics at baseline for the whole group, and according to whether patients were in remission or not at the end of follow-up

\begin{tabular}{|c|c|c|c|c|c|c|c|}
\hline \multirow{2}{*}{ Male sex n \% } & \multicolumn{2}{|c|}{$\begin{array}{c}\text { Whole group } \\
\mathrm{n}=58\end{array}$} & \multicolumn{2}{|c|}{$\begin{array}{c}\text { No remission } \\
\mathrm{n}=38\end{array}$} & \multicolumn{2}{|c|}{$\begin{array}{c}\text { Remission } \\
\mathrm{n}=20\end{array}$} & \multirow{2}{*}{$\frac{\mathrm{p} \text {-value }}{0.22}$} \\
\hline & 42 & $72 \%$ & 25 & $66 \%$ & 17 & $85 \%$ & \\
\hline Age* yrs $^{*}$ & 11 & (1.9) & 11 & $(2.0)$ & 11 & $(1.8)$ & 0.77 \\
\hline $\begin{array}{l}\text { Prior use of inhaled } \\
\text { corticosteroids } \mathrm{n} \%\end{array}$ & 29 & $50 \%$ & 21 & $55 \%$ & 8 & $40 \%$ & 0.41 \\
\hline $\begin{array}{l}\text { Prior use of } \\
\text { cromoglycate } \mathrm{n} \%\end{array}$ & 28 & $48 \%$ & 20 & $53 \%$ & 8 & $40 \%$ & 0.42 \\
\hline $\mathrm{FEV}_{1}^{*} \%$ pred & 76 & $(10.8)$ & 76 & $(9.7)$ & 76 & $(12.8)$ & 0.95 \\
\hline Postbronchodilation $\mathrm{FEV}_{1} * \%$ pred & 94 & $(11.4)$ & 94 & $(9.1)$ & 94 & $(15.2)$ & 0.95 \\
\hline Morning PEFR $* l \cdot \mathrm{min}^{-1}$ & 287 & $(73)$ & 291 & $(78)$ & 280 & $(59)$ & 0.60 \\
\hline $\mathrm{PD}_{20} * * \mu \mathrm{g}$ histamine & 21.5 & $(8,38)$ & 21 & $(9,35)$ & 25.5 & $(8,45)$ & 0.36 \\
\hline $\begin{array}{l}\text { Days in two weeks with } \\
\text { symptoms** }\end{array}$ & 4 & $(1,9)$ & 6 & $(2,9)$ & 2.5 & $(0,4)$ & 0.045 \\
\hline
\end{tabular}

*: data presented as mean, and SD in parenthesis; **: median, and quartiles in parenthesis. $\mathrm{FEV}_{1}$ : forced expiratory volume in one second; $\%$ pred: percentage of predicted; PEFR: peak expiratory flow rate; $\mathrm{PD}_{20}$ : provocative dose producing a $20 \%$ fall in $\mathrm{FEV}_{1}$.

measurements from the visits at and after 18 months. A t-test was then used to test whether the average rate of change across subjects (the average slope of the individual regressions) was significantly different from zero. To assess whether the rate of reporting of symptoms and of additional beta $a_{2}$-agonist was changing after 18 months, a simple linear regression was fitted to the rates at each visit, and the hypothesis that the slope of this regression is zero was tested.

Fisher's exact test, the two-sample t-test or the Wilcoxon test were used to assess for factors that were predictive of remission. For all tests undertaken, p-values are only reported when $<0.2$.

\section{Results}

\section{Clinical signs}

The number of days on which symptoms were recorded during the 14 day period prior to a clinic visit is used as a measure of symptom burden. Figure 1 shows the percentages of patients by the number of days affected. Symptom burden decreased over time during the first 18 months. Thereafter, about one-third of patients reported symptoms on at least one day during the 2 week period prior to each clinic visit, although there was evidence of marginal significance $(p=0.06)$ that this rate may still have been decreasing slowly during the period between 18 and 36 months.

At baseline, $50 \%$ of patients reported no use of additional beta ${ }_{2}$-agonist during the 14 days prior to the clinic visit. By 18 months, $83 \%$ of patients reported no use. There was no further improvement between 18 and 36 months.

Fourteen of the 58 patients $(24 \%)$ received a total of 26 courses of prednisolone. This represents an average of 0.17 courses per patient-year of treatment. This rate was fairly constant from year to year: 0.16 courses in the first year, 0.20 in the second, and 0.13 in the third.

One patient was hospitalized because of severe asthma symptoms for 7 days after 18 months of treatment. $\mathrm{He}$ was treated with prednisolone, nebulized beta ${ }_{2}$-agonist and theophylline $i v$.

Twenty five patients (43\%) had absences from school due to asthma. The total days absent was 293, representing 1.9 days per patient-year of treatment with beta ${ }_{2}$-agonist plus corticosteroid. This remained stable from year to year: 1.8 days in the first year, 2.0 in the second, and 1.5 in the third.

\section{Lung function measurements}

Average prebronchodilation $\mathrm{FEV}_{1}$ had increased from $76 \%$ predicted at baseline to $86 \%$ at 4 months, and did not improve further over time. Average postbronchodilator $\mathrm{FEV}_{1}$, showed an increase from 94\% at baseline to $97 \%$ by 2 months, after which it remained stable during the complete follow-up period.

There was an acute effect of treatment in raising PEFR by $36.6 l \cdot \mathrm{min}^{-1}$ between baseline and 2 months. Thereafter, the upward trend in both pre- and postbronchodilation PEFR (averaging $12.3 l \cdot \mathrm{min}^{-1}$ per year between 18 and 36 months, $\mathrm{p}=0.03$ ) was similar to that expected due to the children's growth [16]. The average evening PEFR (before bronchodilation) showed the same trend, being consistently between the pre- and postbronchodilation morning levels.

The geometric mean $\mathrm{PD}_{20}$ histamine increased steadily over time, and reached a plateau at a subnormal level (just below $80 \mu \mathrm{g}$ ) between 20 and 24 months (mean increase 2.1 doubling doses (DD)) (fig. 2).

The average standard deviation in day-to-day variability of the morning PEFR before bronchodilation was reduced by $5.9 l \cdot \mathrm{min}^{-1}$ within 2 months, and stabilized after 8 months at a level of about $20 \mathrm{l} \cdot \mathrm{min}^{-1}$, which was 


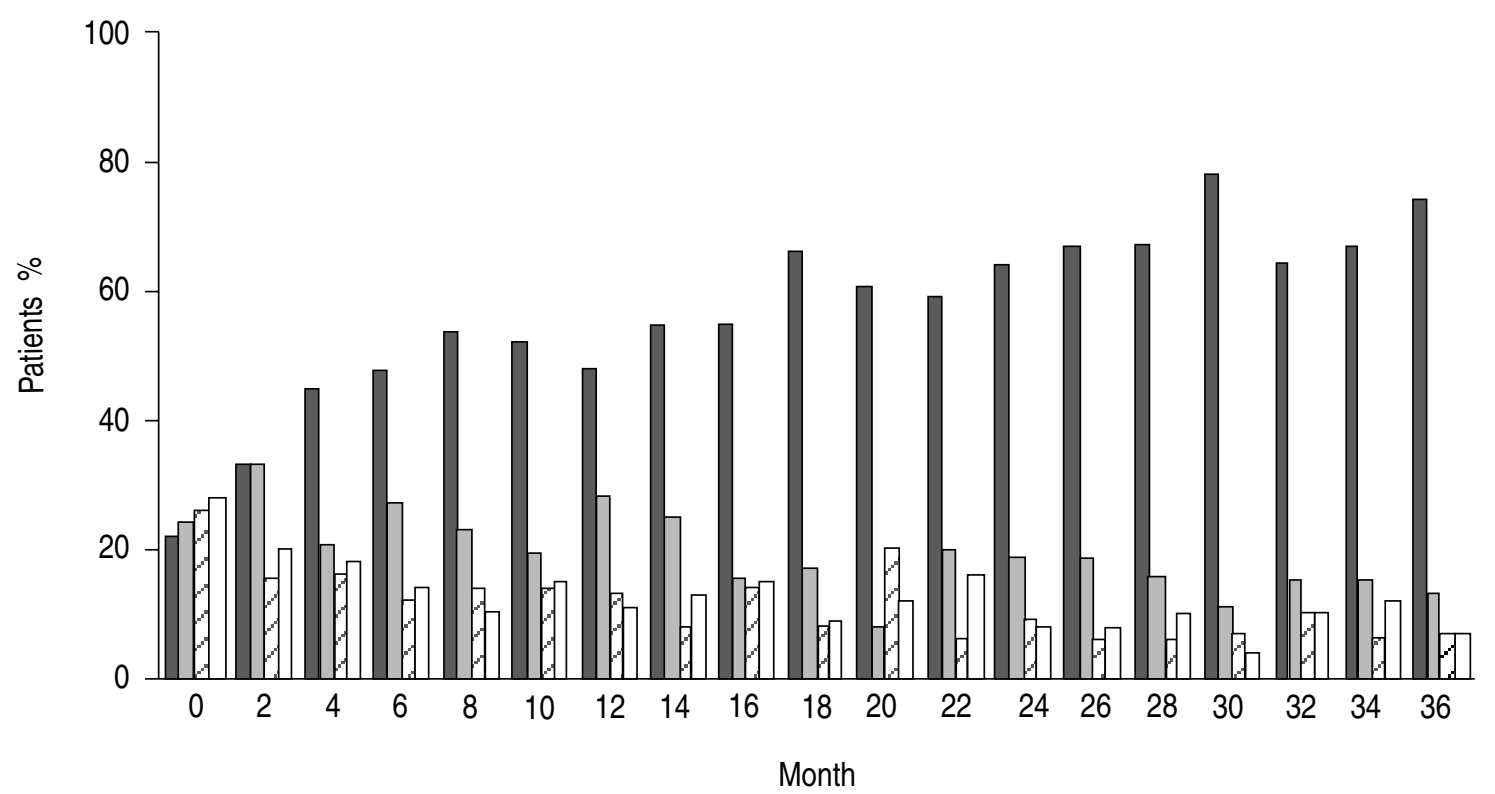

Fig. 1. - Percentage of patients plotted against days with symptoms during two weeks over the follow-up period. $\square: 0$ days; $\square: 1-3$ days; $\square: 4-7$ days; $\square: 8-14$ days.

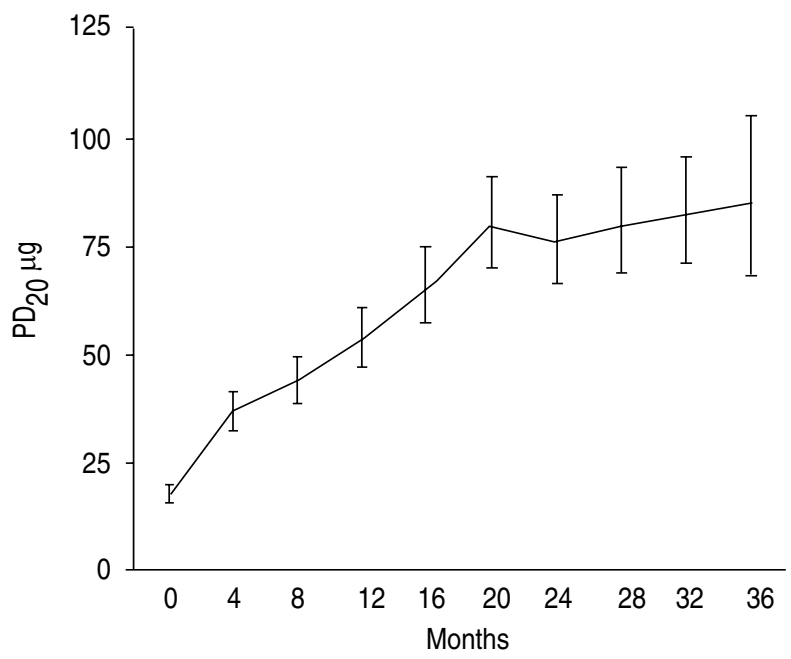

Fig. 2. - Geometric mean $\mathrm{PD}_{20}$ histamine (SEM) increased steadily over time, and reached a plateau at a subnormal level (just below $80 \mu \mathrm{g}$ ) between 20 and 24 months, (mean increase 2.1 doubling doses). $\mathrm{PD}_{20}$ : provocative dose of histamine producing a $20 \%$ fall in forced expiratory volume in one second.

maintained until the end of the study period. Average change in PEFR between morning and afternoon measurements declined from $24.7 \mathrm{l} \cdot \mathrm{min}^{-1}$ at baseline to a level of about $18 l \cdot \mathrm{min}^{-1}$ after 8 months, and was maintained thereafter.

\section{Remission}

Of the 58 patients, $35(60 \%)$ experienced at least one period of symptomatic remission. The number of patients in remission increased with time on treatment. For instance, in the first 8 months of the study, seven patients $(12 \%)$ were in a remission; in the eight month periods prior to the visits at 20,28 and 36 months, the numbers in remission were $10(17 \%), 15(26 \%)$ and 13
(34\%, of those completing 36 months), respectively. However, the majority of patients achieving a remission as we had defined (an 8 month period without symptoms) (23 of the $35,(66 \%))$ had a relapse at a later stage, during the further follow-up.

At the end of the follow-up, 20 patients $(35 \%)$ were in remission. Of these, only 8 also had normal $\mathrm{PD}_{20}$ histamine $(>150 \mu \mathrm{g})$ and $\mathrm{FEV}_{1}(>90 \%$ predicted $)$ at the clinic visits over the previous eight months; 3 other patients had one, but not both, levels of $\mathrm{PD}_{20}$ histamine or $\mathrm{FEV}_{1}, \%$ predicted within the normal range at each visit. Comparison of baseline characteristics for patients in remission at the end of follow-up versus those who were not, showed that the former group reported significantly fewer days with symptoms at baseline (table 1). $\mathrm{FEV}_{1} \%$ predicted and postbronchodilator response showed no predictive value, and there is little difference in average $\mathrm{PD}_{20}$ histamine or PEFR levels.

\section{Side effects}

Twenty patients mentioned side-effects. All sideeffects were minor (cough, hoarseness, trembling) and were never a reason to stop study medication. In a separate paper, MERKus et al. [17] described the increase in height of the study patients in two of the three centres compared with longitudinal data of matched healthy controls, and showed no difference.

\section{Discussion}

This study describes the results of 28-36 months treatment with inhaled corticosteroid plus inhaled beta ${ }_{2}$ agonist on asthma in children. Average levels of all lung function measurements had stabilized after 20 
months of treatment, but at levels outside the normal range. Symptom burden reduced markedly over the first few months of treatment, but there may still have been a continued slow improvement beyond 18 months, as evidenced, in particular, by the increasing numbers achieving symptomatic remission. In general, individual patients improved with treatment: the majority showed a decrease in symptoms, $\mathrm{PD}_{20}$ levels were improved in all but four patients, and $\mathrm{FEV}_{1}$ in all but five. We found no pretreatment characteristics which identified a subgroup of patients for whom the treatment had no benefit. Although both symptoms and objective measurements improved over time, a permanent remission was rarely seen, and mean levels of airway calibre and airway responsiveness remained abnormal.

This is the first study in children to have considered whether a long-lasting remission from asthma can be induced by drug treatment. Although it has been shown that about $50 \%$ of children will reach a remission spontaneously in puberty or adolescence [18-21] (especially amongst those with mild asthma), it is an important question, because children with more severe asthma are more likely to suffer from asthma in adulthood [2022]. We arbitrarily defined a symptomatic remission as a period of 8 months without any symptoms reported. During 28-36 months of treatment with inhaled corticosteroid plus beta 2 -agonist, 35 patients $(60 \%)$ achieved a remission, although fewer (20 patients, $(35 \%))$ were in a remission at the end of the follow-up, and only about half of these had normal levels of $\mathrm{PD}_{20}$ histamine and $\mathrm{FEV}_{1} \%$ predicted at that time. Lower symptom burden at baseline seemed to be the only predictor of patients likely to reach remission; notably measures of lung function had no predictive value.

It is unlikely that the patients reaching remission had had a spontaneous recovery, since they had moderate asthma which required maintenance treatment for a long period before entering the study. In puberty and adolescence a fair percentage of children become symptom free. Usually these children have mild asthma [23]. Also, comparison of the number of remissions during the comparative phase of the study showed that only 7 patients $(12 \%)$ of those taking beta ${ }_{2}$-agonist alone achieved remission, compared with 20 (34\%) of those taking corticosteroid plus beta ${ }_{2}$-agonist. However, our results also showed that two-thirds of patients achieving a symptomatic remission suffered a relapse. Thus, although 28-36 months of treatment with inhaled corticosteroid improves both symptoms and objective measures of lung function, it does not cure asthma. This is underlined by our findings in a subsequent study, in which cessation of inhaled corticosteroid from our cohort was followed by a rapid increase in symptoms and a deterioration in lung function [24].

Recently JUNIPER et al. [7] investigated the effect of long-term therapy with inhaled corticosteroid on remission rate in adults. In this double-blind, randomized study, 16 adult patients with mild asthma received 200 $\mu \mathrm{g}$ budesonide b.i.d., 16 others received placebo. The steroid-group showed an improvement in symptoms, which was maximal after 9 months of treatment. In 8 patients, airway responsiveness reached a plateau after 6-12 months on budesonide. Nevertheless, mean provocative concentration of methacholine producing a $20 \%$ fall in $\mathrm{FEV}_{1}\left(\mathrm{PC}_{20}\right)$ had increased by $2 \mathrm{DD}$, but had not yet stabilized after 12 months on this treatment. Five patients on budesonide $(31 \%)$ reached a value of $\mathrm{PC}_{20}$ methacholine within the normal range $\left(>8 \mathrm{mg} \cdot \mathrm{ml}^{-1}\right)$. They were among those who became symptom-free and no longer needed additional bronchodilator. Our results differ in some respects from those of JUNIPER et al. [7]. We found that mean $\mathrm{PD}_{20}$ histamine stabilized after 20 months; this difference might be explained by the longer duration of treatment, and the higher dose of inhaled corticosteroid taken. Findings regarding normalization in airway responsiveness were similar: even after 36 months on inhaled corticosteroid, airway responsiveness remained abnormal in the majority of patients.

HAAHTELA et al. [8] studied 103 newly detected adult asthmatics in a 22 month study, and randomized them to budesonide $600 \mu \mathrm{g}$ b.i.d or terbutaline $375 \mu \mathrm{g}$ b.i.d. In the patients on budesonide, symptoms and the need for additional bronchodilator decreased within one week after randomization, but did not diminish thereafter. They did not provide data on the rate of patients who became symptom-free after such a long treatment period. Provocative concentration of histamine producing a $15 \%$ fall in $\mathrm{FEV}_{1}\left(\mathrm{PC}_{15}\right)$ histamine showed a marked increase within 6 weeks on budesonide, and a further increase at a slower rate thereafter. At 16 months a plateau was reached at a mean value of 1.6 DD above baseline. Since HaAHTELA et al. [8] used a different method to assess airway responsiveness, the results are not fully comparable. However, the shift of $\mathrm{PC}_{15}(1.6$ $\mathrm{DD}$ after $1 \mathrm{yr}$ ) is in the same range as the shift of $\mathrm{PC}_{20}$ in the study of JUNIPER et al. [7] (2 DD after $1 \mathrm{yr}$ ), and of $\mathrm{PD}_{20}$ in our study (2.1 DD after 20 months).

These findings suggest that the underlying inflammatory process is still present after years on inhaled corticosteroid. Little is known about the effect of inhaled corticosteroid on airway morphology in asthma. Some short- and long-term studies in adult asthmatic patients show a beneficial effect of inhaled corticosteroid on characteristics of airway inflammation $[25,26]$. Studies in children are lacking.

What do these findings imply for clinical practice? It seems that long-term follow-up of airway calibre, bronchodilator response, and airway responsiveness are not useful guides for a strategy in the treatment of asthma, once inhaled corticosteroid has been started. Almost all patients will improve, both in symptoms and in objective measurements, independent of the level from which they start. A normalization of airway responsiveness will only occur in a minority of patients. Treatment should, therefore, be aimed at a symptomatic remission, i.e. normalization in symptoms, without need of additional bronchodilator. This is in agreement with recently published consensus reports on the treatment of asthma, in which a normalization of airway sensitivity was not stated as an aim to achieve [11-13]. In our study, all patients used both inhaled corticosteroid and beta $_{2}$-agonist on a regular basis. It is uncertain to what 
extent a normalization in symptoms can be reached with inhaled corticosteroid as the only regular drug taken. Therefore, new long-term studies in which the effect of regular treatment with inhaled corticosteroid only is compared with inhaled corticosteroid plus beta $_{2}$-agonist are needed to answer this question.

Acknowledgement: The authors thank the patients and parents for their participation; the pharmaceutical companies Astra Pharmaceuticals, Boehringer Ingelheim and Glaxo for providing study medication in identical metered dose inhalers; P. Merkus for his analyses of growth; and A. Hartman-Bochdanek, A. Rikkengaavan der Pols, S. Smit and F. Spoel for their secretarial support.

The Dutch Chronic Nonspecific Lung Disease Study group consists of a steering committee (K.F. Kerrebijn Ph.H. Quanjer and H.J. Sluiter ${ }^{\dagger}$ ), of members from the Departments of Pulmonary Medicine of the University Hospital of Amsterdam (E.M. Pouw, D.F.M.E. Schoonbrood, C.M. Roos, H.M. Jansen), Groningen (P.L.P. Brand, A. de Gooijer, H.A.M. Kerstjens, D.S. Postma, Th.W. van der Mark, H.J. Sluiter ${ }^{\dagger}$, G.H. Köeter), Leiden (P.M. de Jong, P.J. Sterk, A.M.J. Wever, J.H. Dijkman), Nijmegen (P.N.R. Dekhuijzen, H. Folgering, C.L.A. van Herwaarden), Rotterdam (S.E. Overbeek, J.M. Bogaard, C. Hilvering), and Utrecht (S.J. Gans, H.J.J. Mengelers, B.van der Bruggen, J. Kreukniet), from the Departments of Paediatrics, subdivision Paediatric Respiratory Medicine of the Sophia children's hospital, Rotterdam (E.E.M. van Essen-Zandvliet, K.F. Kerrebijn), the Juliana children's hospital, The Hague (E.J. Duiverman, J.M. Kouwenberg, J.E. Prinsen) and the University Hospital of Groningen (H.J. Waalkens, J. Gerritsen, K. Knol), from the Department of Allergology, University of Groningen J.G.R. de Monchy), from the Department of General Practice, University of Leiden (A.A. Kaptein, F.W. Dekker), and from the Department of Physiology, University of Leiden (P.J.F.M. Merkus, Ph.H. Quanjer). Scientific counsel: S.J. Pocock, N.J. Robinson (London, UK), M.D. Hughes (Boston, USA), B.R. Bleecker, D.A. Meyers (Baltimore, USA).

\section{References}

1. Djukanovic R, Roche WR, Eilson JW, et al. - State of the art. Mucosal inflammation in asthma. Am Rev Respir Dis 1990; 142: 434-457.

2. Laitinen LA, Heino M, Laitinen A, Kava T, Haahtela T. - Damage of the airway epithelium and bronchial reactivity in patients with asthma. Am Rev Respir Dis 1985; 131: 599-606.

3. Jeffery PK, Wardlaw AJ, Nelson FC, Collins JV, Kay AB. - Bronchial biopsies in asthma. Am Rev Respir Dis 1989; 140: 1745-1753.

4. Beasley R, Roche WR, Roberts JA, Holgate ST. - Cellular events in the bronchi in mild asthma and after bronchial provocation. Am Rev Respir Dis 1989; 139: 806-817.

5. Djukanovic R, Wilson JW, Britten KM, et al. - Effect of an inhaled corticosteroid on airway inflammation and symptoms in asthma. Am Rev Respir Dis 1992; 145: 669-674.

6. Laitinen LA, Laitinen A, Haahtela T. - A comparative study of the effects of an inhaled corticosteroid, budesonide, and a beta ${ }_{2}$-agonist, terbutaline, on airway inflammation in newly diagnosed asthma: a randomized, double-blind, parallel group, controlled trial. J Allergy Clin Immunol 1992; 90: 32-42.

7. Juniper EF, Kline PA, Vanzieleghem A, Ramsdale EH, O'Byrne PM, Hargreave FE. - Effect of long-term treatment with an inhaled corticosteroid (budesonide) on airway hyperresponsiveness and clinical asthma in nonsteroid-dependent asthmatics. Am Rev Respir Dis 1990; 142: 832-836.
8. Haahtela T, Järvinen M, Kava T, et al. - Comparison of a beta ${ }_{2}$-agonist, terbutaline, with an inhaled corticosteroid, budesonide, in newly detected asthma. $N$ Engl J Med 1991; 325: 388-392.

9. Van Essen-Zandvliet EEM, Hughes MD, Waalkens HJ, Duiverman EJ, Pocock SJ, Kerrebijn KF, and the Dutch Chronic Nonspecific Lung Disease study group. - Effects of 22 months treatment with inhaled corticosteroids and/or beta ${ }_{2}$-agonists on lung function, airway responsiveness and symptoms in children with asthma. Am Rev Respir Dis 1992; 146: 547-554.

10. Van Essen-Zandvliet EEM, Kerrebijn KF. - The effect of anti-asthma drugs on bronchial hyperresponsiveness. Immunol Allergy Clin NA 1990; 10: 483-501.

11. National Heart Lung and Blood Institute. Guidelines for the diagnosis and management of asthma. Expert panel report. J Allergy Clin Immunol 1991; 88 (Suppl. 2:3).

12. Warner JO, Götz M, Landau LI, et al. - Management of asthma: a consensus statement. Arch Dis Child 1989; 64: 1065-1079.

13. Warner JO, et al. - Asthma: a follow-up statement from an international paediatric asthma consensus group. Arch Dis Child 1992; 67: 240-248.

14. Gerritsen J, Köeter GH, Postma DS, Schouten JP, Knol K. - Prognosis of asthma from childhood to adulthood. Am Rev Respir Dis 1989; 140: 1325-1330.

15. Duiverman EJ, Neijens HJ, van Strik R, Affourtit MJ, Kerrebijn KF. - Lung function and bronchial responsiveness in children who had infantile bronchiolitis. Ped Pulmonol 1987; 3: 38-44.

16. Weng T, Levison H. - Standards of pulmonary function in children. Am Rev Respir Dis 1969; 99: 879-894.

17. Merkus PJFM, van Essen-Zandvliet EEM, Duiverman EJ, van Houwelingen HC, Quanjer PhH, Kerrebijn KF. - Effects of inhaled corticosteroids on growth of stature in asthmatic adolescents. Pedatrics 1993; 91: 1121-1126.

18. Blair H. - Natural history of childhood asthma. Arch Dis Child 1977; 52: 613-619.

19. Bronnimann S, Burrows B. - A prospective study of the natural history of asthma. Remission and relapse rates. Chest 1986; 90: 480-484.

20. Martin AJ, McLennan LA, Landau LI, Phelan PD. The natural history of childhood asthma to adult life. $\mathrm{Br}$ Med J 1980; 280: 1397-1400.

21. Kelly WJW, Hudson I, Phelan PD, Pain MC, Olinsky A. - Childhood asthma in adult life: a further study at 28 years of age. $\mathrm{Br}$ Med $J$ 1987; 294: 1059-1062.

22. Williams HE, McNicol KN. - Prevalence, natural history and relationship of wheezy bronchitis and asthma in children. An epidemiological study. Br Med J 1969; iv: 321-325.

23. Roorda RJ. - Features of the outcome of childhood asthma. Thesis, 1992; Groningen, The Netherlands.

24. Waalkens HJ, van Essen-Zandvliet EEM, Hughes MD, et al. - Cessation of long-term treatment with inhaled corticosteroid (budesonide) in children with asthma results in rapid deterioration. Am Rev Respir Dis (in press).

25. Lundgren R, Söderberg M, Hörstedt P, Stenling R. Morphological studies of bronchial mucosal biopsies from asthmatics before and after 10 years of treatment with inhaled steroids. Eur Respir J 1988; 1: 883-889.

26. Jeffery PK, Godfrey RW, Ädelroth E, Nelson F, Rogers A, Johansson S-A. - Effects of treatment on airway inflammation and thickening of basement membrane reticular collagen in asthma. Am Rev Respir Dis 1992; 145: 890-899. 